\title{
Flores Vidales, Alfredo (CoOrd.) (2011). Adolescentes en Conflicto con la ley. iLo residual del sistema? MéXico: Grupo Metonimia/INDESOl.
}

\author{
Alain Basail-Rodríguez
}

E n el conjunto de los estudios sobre juventudes, este libro destaca por presentar el trabajo de investigación e intervención realizado por el Grupo Metonimia A.C. en el Centro de Internamiento Especializado para Adolescentes Villa Crisol en Berriozábal, Chiapas. Alfredo Flores coordina un equipo integrado por Wendolyn Valencia, Laura Angélica San Vicente, Lorena Cruz, Mariana Altúzar, Walter Abarca, Juan David Bautista, Carlos Hernández, Selene Tovilla, David Bautista y Carlos Hernández.

El lector puede advertir desde las primeras páginas del texto la sensibilidad de los autores al dedicarlo a los adolescentes olvidados que no imaginan que puedan creer en ellos y a los que trabajan por reconstruir tejidos sociales. En la introducción, Flores señala la relevancia de la participación de los adolescentes en actividades ilegales y, como otro indicador de un síntoma social más complejo, advierte sobre el comienzo de sus carreras delictivas a edades tempranas. De ahí el compromiso con "reflexionar acerca del lugar en que [la sociedad] ha colocado a su población más joven" (p. 12), yendo a la raíz de la constitución de sus agentes, a las maneras en que los adolescentes en conflicto con la ley se erigen en las tendencias destructivas y del delito.

Para recortar el síntoma social, se mira entre fenómenos que emergen, son reprimidos o inhibidos y que designan una "manera de vivir" con un conjunto de experiencias, posibilidades y riesgos. Siguiendo el concepto del discurso clínico-psicoanalítico, se buscan los sentidos ocultos de lo que se podría llamar el "síntoma juvenil," es decir, un fenómeno moral y político relativo a los jóvenes. Entonces, la apuesta crítica pasa por oponerse a la naturalización de lo socialmente construido con relación a la situación de los jóvenes, a los lugares comunes de expresiones ideológicamente inmovilizadoras tales como el "sentimiento de abandono", la "ausencia de guía", la "crisis de valores", el "fracaso escolar" o la "crisis de sociabilidad".

En particular, interesan los jóvenes infractores como victimarios y víctimas de la violencia estructural que se expresa agudamente en Chiapas. Como residuos humanos, estos jóvenes están destinados a contenedores que, en tanto mecanismos de control y exclusión, fungen como instituciones totales, es decir, espacios sin sujetos a partir del aniquilamiento, apropiación o estigmatización de los internos. El encargo de la institución carcelaria es "aprisionar en el vacio de sentido" a los parias "culpables," "indignos" y "peligrosos" por violar el pacto social. Ahí radica su paradoja constitutiva en cuanto dispositivo concreto de ordenamiento social — disciplina, vigilancia y castigo - : en nombre de la protección — de la sociedad y de ellos mismos-, se niega la vida; en busca de la

Alain Basail Rodríguez. Centro de Estudios Superiores de México y Centroamérica de la Universidad de Ciencias y Artes de Chiapas. Correo electrónico: alain.basail@unicach.mx.

Recibida: 26 de enero de 2016. 
reinserción social, se reproduce la segregación y la estigmatización. Por ello, toda cárcel como la de Villa Crisol se convierte en un espacio de relaciones de poder en una situación límite, de lucha por la vida, por la identidad - existir socialmente- y por la autonomía del sujeto que busca sobrevivir anímica y dignamente.

Tres partes conforman la obra para dar cuenta del síntoma, su diagnóstico y la intervención realizada durante el año 2010. La primera es de discusión de las tesis generales sobre el papel de la familia en la constitución de la adolescencia, sus malestares y su carácter residual en la sociedad. En la segunda se profundiza en la estrategia metodológica de la investigación a través del análisis cualitativo de las instituciones carcelarias y, en particular, de los reclusorios de menores, así como en la intervención institucional, mediante entrevistas a jóvenes y familiares, observación etnográfica y dos Grupos Terapéuticos de Reflexión (GTR) donde se les da el lugar de sujetos. El tercer y último apartado sumerge al lector en la subjetividad de los adolescentes, en sus síntomas vividos y en los percibidos por los propios investigadores; profundiza sobre las estructuras familiares, las biografías y los procesos de simbolización abiertos por los caminos del arte. Los GTR fueron el dispositivo metodológico de intervención para reorientar las tendencias transgresoras, destructivas y de muerte hacia la creatividad apostando por una edificación de la vida y del lazo social a partir de la resignificación de sus pulsiones de muerte.

Además, el libro cuenta con unas consideraciones finales y una addenda en la que se analiza la evolución de la justicia para adolescentes con sus desfases en la realidad de los centros de reclusión. Este apartado revela una serie de aristas de la dinámica de la vida del penal de Berriozábal a partir de un conocimiento detallado de la realidad interna y una mirada crítica que sutura las legitimaciones del discurso dominante en Chiapas. Walter Abarca, quien fungiera como director del Centro, muestra los vacios jurídico-legales en materia de tratamiento juvenil y las prácticas reales del modelo penal, punitivo y securitizador.
Su perspectiva abre la posibilidad de una profunda reforma de este espacio de frontera que advierte de las imposibilidades de la sociedad y, en concreto, recomienda ampliar los sistemas de control social.

Adolescentes en conflicto con la ley... cimbra al lector humanista con los testimonios de los jóvenes y el trabajo comprensivo de los investigadores. La mirada psicoanalítica se enfoca en la estructuración del sujeto desde las relaciones primarias de su vida durante la infancia. Busca esas formas estructurantes en las historias entretejidas por los adolescentes y sus familiares, por develar narrativamente distintas configuraciones de los vínculos familiares y los sentidos éticos que someten a pulsiones de destrucción y de muerte. El socioanálisis parte de la escucha analítica y apunta al lenguaje oculto, a la subjetividad donde se encuentran las raíces de los actos transgresivos de sujetos que son un tejido de discursos. En la búsqueda de algo estructural en su psiquismo más fundante, del saber que es propio de quien lo padece, emergen las discursividades constitutivas de los sujetos.

Entre algunos de sus hallazgos sobre las vicisitudes edípicas de los adolescentes y las fracturas de sus marcos temporales de experiencia generadas desde la familia, se destacan: la herencia del discurso familiar en la estructuración psíquica de los sujetos de la transgresión; el no reconocimiento de la responsabilidad de los padres para implementar prohibiciones, establecer el orden y un sentido no destructivo; la complicidad o permisibilidad del orden materno que consiente al sujeto transgredir el deseo del otro reconociendo solamente la ley de su deseo; o la complacencia silenciosa del padre, que carece de la ley que exige el joven para que la ley de su deseo sea sometida a la del otro. Precisamente, estos sujetos oscilan entre la idealización y el repudio de aquella figura materna que ha aceptado el orden del otro, razón por la cual desafían al padre/Estado pues recusan su ley.

El conflicto de los jóvenes con la ley es el correlato de otros conflictos con, por ejemplo, el mercado laboral, el consumo de bienes materiales y simbólicos, la política institucional - alejados de sus estéricas 
terrenas-, las escuelas, la fe institucionalizada y la familia. Los conflictos adquieren sentido para regular las relaciones entre el deseo y la norma (ley) $\mathrm{y}$, al no dirimirse, aumentan la angustia, la ansiedad (defensa), la frustración (agresión) o el desencanto de la política, del derecho y de la vida misma. Por ello, el análisis de los relatos biográficos podría ser más perspicaz al profundizar en las trayectorias educativas, laborales y jurídicas para contribuir a la apertura reflexiva a los porqués. De esta manera, el discurso juvenil revelaría más indicios sobre las condiciones del mundo social como un inmenso depósito de violencia acumulada.

Entre las luchas de poder y las relaciones de dominación/subordinación se abren intersticios de resistencias, de disentimientos que manifiestan actitudes culturales de denuncia, voces de otros marginados y diferencias negadas. Por ejemplo, la ley prohíbe, reprime y sublima desviando el deseo a un comportamiento aceptado por la normatividad como código moral. La ley es políticamente activa y está ideológicamente comprometida. Sin duda, el desafío de la ley por parte de los jóvenes tiene como función la burla (p. 5l). La ley es un correlato del desafío del joven, la necesita para confirmar su acto transgresivo y hacer notar que puede franquear las prohibiciones instituidas simbólicamente. El derecho impone una determinada moral, procedimientos de control y penalización que adquieren consecuencias no queridas - estigmatización, identidades deterioradas, corrupción, violencia-. Estas consecuencias evidencian las ambivalencias morales del orden social: por un lado, estigmatización, represión y control en nombre de la "moral pública" y, por otro lado, reinserción social, necesidad de riesgos y tolerancia socialmente extendida.

Los conflictos con la ley plantean los desafíos institucionales y de las políticas públicas porque los jóvenes son "los más olvidados en los programas sociales" (p. 15). El conflicto con la ley del padre/ Estado es un conflicto moral que corta las trayectorias biográficas juveniles. Esto indica la falta de una visión del derecho como instrumento de transformación social, más que de control de recursos humanos y naturales; asimismo, la necesidad de un cambio real de relaciones en la ley, de represiva a restitutiva, como un instrumento de resolución de conflictos y gestión de disputas. Ello a partir del conocimiento de la naturaleza de las relaciones sociales y de respeto a los derechos humanos en las prácticas reales.

Flores discute sobre el malestar en la adolescencia en el capítulo 2 en términos de "crisis de la adolescencia", "momento crítico o frágil de reestructuración y reorganizaciones”. Él advierte ese malestar de crecimiento, y no de carencia, a partir de la confrontación con la imagen que los jóvenes tienen de sí mismos, entre generaciones y con el futuro al tener que decidir sobre su propia vida. Y lo relaciona con el malestar profundo que lo genera y se manifiesta en los procesos de socialización, como movimientos transitorios o rituales de transformación entre el orden y el caos de nuestra cultura.

Por ello, las posibilidades de integración social durante el crecimiento dependerán de la maduración y elaboración de conflictos emocionales, de las definiciones de responsabilidad, de la construcción de una nueva moral y de nuevos valores e identificaciones en las búsquedas de representaciones y de pertenencia, protección y seguridad. Sin embargo, ante los desajustes entre las exigencias culturales y la perspectiva individual que configuran los componentes trágicos de la cultura, emergen la violencia, el dolor y la angustia, angustia que cada joven recluido drena con la sangre de cada tatuaje y la excitación de toda adicción (p. 89).

La invitación del subtítulo de la obra a pensar el signo residual de los jóvenes en el sistema social es explicitada en el capítulo 3 por Lorena Cruz. En el mismo se discute el concepto de adolescencia residual siguiendo las ideas de Bauman, ${ }^{1}$ que representan lo que la sociedad produce y extraña. Sin embargo, no se cae en pesimismo sobre el "hombre sin vínculos" y las "relaciones de bolsillo". No es igual de apropiado el análisis de la participación de las nuevas tecnologías y de los medios de comunicación en la conformación de la adolescencia, porque no argumenta ni discute la 
posición tecnofóbica que pareciera asumirse. Asimismo, la mirada sobre las dinámicas identitarias es esencialista, romántica y reduccionista al contraponer un mundo globalizado con un mundo indígena idealizado (p. 111). La pregunta sobre lo residual del sistema lleva a pensar en qué tipo de sujeto juvenil se ha constituido en los últimos veinte años

Los discursos de los jóvenes permiten leer los profundos cambios socioculturales de la sociedad que se instaura sobre relaciones de institucionalidad prohibitiva necesarias para mantener el orden (p. 79). La sociedad mexicana y, en particular, la del sur del país, vive el melodrama del poder policiaco que advierte sobre las complicidades que el crimen establece con el poder institucionalizado. Perdida la mesura entre deseo y prohibición, los hijos de la sociedad neoliberal han vivido en el reinado de la desprotección social y civil. Los límites a la existencia se ahondan en medio del tránsito hacia la razón securitaria y al estado policial que dice encarnarla. Empero, la búsqueda obsesiva del impulso inmunitario supone implícitamente los límites de una vuelta al tiempo social único y homogéneo.

Sin duda, estos jóvenes son víctimas de la creación artificial de riesgos. Al elevarse el umbral de riesgo, se construyen sujetos juveniles peligrosos que son los chivos expiatorios del bloqueo al crecimiento de la sociedad. La criminalización y la estigmatización de los jóvenes marcan el olvido de sus proyectos de vida y los hechizos que acentúan la desconfianza en el futuro, su opacidad. Agudamente lo apunta Valenzuela Arce cuando dice que El futuro ya fue ${ }^{2}$ porque se apropiaron del futuro de los jóvenes o los expropiaron del mismo con tantos límites en la realidad del presente que es su futuro. La falta de expectativas y el escepticismo los sitúan en el túnel de la crisis porque, como dice El Pingüino, uno de los jóvenes colaboradores, "andas muerto en vida" (p. 208).

El contexto de afirmación/negación de los jóvenes frente al otro es de violencia, pérdida, duelo, diferenciación en el interior de la comunidad. ¿Cómo saltar la fragilidad, la fragmentación, la denegación, la represión, los conflictos y la violencia? Otro lugar de los jóvenes en la sociedad, para que ésta exista como tal, pasa por comprender que lo juvenil no es una fase social, sino una forma moral en tanto que decisión y apertura ética a la condición común de coautores de los vínculos sociales.

En este sentido, los autores confirman la vieja lección de la antropología y del psicoanálisis en cuanto a la necesidad de ejemplos en el ejercicio de la paternidad como medio de canalizar las energías agresivas masculinas porque, de lo contrario, existirá mayor probabilidad de manifestar esas energías a través de la criminalidad y la violencia. La familia nos inscribe en el orden cultural, pero la estructura, el tamaño, la duración y las modalidades de los vínculos familiares están inmersos en profundos cambios. La llamada crisis de la familia remite a sus modalidades cambiantes con relación a los términos de residencia común, cooperación económica, reproducción y socialización de la descendencia. Más que al derrumbe o la diversificación de un modelo mítico, la familia va hacia derivas disímiles por las tensiones entre dominación masculina y liberación femenina, matrimonio para regular el comportamiento sexual y la libertad sexual, y el control de la natalidad a través de la planeación familiar o las políticas demográficas.

Estas dinámicas alertan sobre la urgencia de políticas familiares que aseguren la protección y asistencia familiar a partir del incremento de la participación de los padres en el cuidado de los hijos y en la vida doméstica. La familia y la vida familiar en torno a la negociación, la cooperación y el compromiso siguen siendo claves para las relaciones entre lo público y lo privado, lo institucional y lo personal.

Al discutir varios de estos elementos, el libro es envolvente y propositivo. Lleva al lector a inscribirse en debates éticos. Muestra esperanza en la restauración del lazo social y en la lucha contra el olvido de la adolescencia a partir de la recuperación de su punto de vista como contribución al diálogo social. Esto lo hace transformando la obsesión fóbica de que toda relación entre diferentes es inmune a través del enfrentamiento mortal con el otro. El texto no se arrumba en la apología de la inseguridad crónica, más bien se enrumba hacia posibilidades de futuro. Tiene una buena estrella 
aunque las incomprensiones, incluidas las de este comentarista, serán parte de su propia historia. Historia en la que se ubica Olvidados. Historias de transgresión, ${ }^{3}$ que amplía el trabajo hacia las familias y las comunidades de los jóvenes.

En resumen, se trata de un libro de una altísima sensibilidad humana y un compromiso intelectual con acciones efectivas por la vida que restituyan la "conectividad" de estos jóvenes, versus la fragmentación y el aislamiento. Su apuesta es, desde una mirada foulcaultiana, invertir la línea del presente para liberar otras posibilidades. Su posición parte de una convicción libertaria a partir de la necesidad de reconocer a los jóvenes como sujetos de derecho, criticando su cosificación.

\section{Notas}

${ }^{1}$ Ver: Bauman, Zygmunt (2005). Vidas desperdiciadas. La modernidad y sus parias. Barcelona: Paidós.

${ }^{2}$ Valenzuela Arce, José Manuel (2009). El futuro ya fue. Socioantropología de l@s jóvenes de la modernidad. México: COLEF/Casa Juan Pablos.

${ }^{3}$ Flores Vidales, Alfredo (coord.) (2011). Olvidados. Historias de transgresión. México: Metonimial INDESOL. 